\title{
Selected Skill Sets As Building Blocks for Secondary-To-Tertiary Education Bridge: A Retrospective Longitudinal Study Among Undergraduate Medical Students
}

\section{Laila Alsuwaidi ( $\nabla$ laila.alsuwaidi@mbru.ac.ae)}

Mohammed Bin Rashid University of Medicine and Health Sciences

\section{Farah Otaki}

Mohammed Bin Rashid University of Medicine and Health Sciences

Amar Hassan Khamis

Hamdan Bin Mohammed College of Dental Medicine, Mohammed Bin Rashid University of Medicine and 15 Health Sciences

\section{Reem AlGurg}

Mohammed Bin Rashid University of Medicine and Health Sciences

\section{Ritu Lakhtakia}

Mohammed Bin Rashid University of Medicine and Health Sciences

\section{Research Article}

Keywords: bridge to university, transition program, undergraduate medical education, academic performance, learning skill sets, self-regulated learning

Posted Date: September 7th, 2021

DOI: https://doi.org/10.21203/rs.3.rs-781321/v1

License: (c) (i) This work is licensed under a Creative Commons Attribution 4.0 International License. Read Full License 
1 Selected skill sets as building blocks for secondary-to-tertiary

2 education bridge: a retrospective longitudinal study among

3 undergraduate medical students

4

5 Laila Alsuwaidi ${ }^{1 *}$ (https://orcid.org/0000-0002-6723-0770),

6 Farah Otaki ${ }^{2}$ (https://orcid.org/0000-0002-8944-4948),

7 Amar Hassan Khamis ${ }^{3}$ (https://orcid.org/0000-0002-8518-3066),

8 Reem AlGurg ${ }^{1,2}$ (https://orcid.org/0000-0002-3135-5352),

9 Ritu Lakhtakia ${ }^{1}$ (https://orcid.org/0000-0002-3549-9986),

$11{ }^{1}$ College of Medicine, Mohammed Bin Rashid University of Medicine and Health Sciences, Dubai, United Arab 12 Emirates.

$13{ }^{2}$ Strategy and Institutional Excellence, Mohammed Bin Rashid University of Medicine and Health Sciences,

Dubai, United Arab Emirates.

${ }^{3}$ Hamdan Bin Mohammed College of Dental Medicine, Mohammed Bin Rashid University of Medicine and

Health Sciences, Dubai, United Arab Emirates.

Short title: Secondary-to-tertiary education bridge in a medical school

\section{*Corresponding Author:}

Laila Alsuwaidi

E-mail: 1aila.alsuwaidi@mbru.ac.ae

Dubai, UAE 


\section{Abstract}

Background: The secondary-to-tertiary education transition is a significant milestone in the students' academic journeys. This is particularly relevant to entry into medical schools, which is characterized by multiple stressors. Although this crucial transition has been repetitively explored, the concept of proactively intervening to support this transition, by fostering SelfRegulated Learning, is still novel. Accordingly, through this study, the authors investigate the efficacy of an online Multi-dimensional Resilience Building Intervention and analyse the association between the students' proficiency of selected skill sets and their academic performance over time.

Methods: A retrospective longitudinal study was conducted on one cohort of undergraduate medical students. The students were offered an online learning and development intervention around four skill sets during the first curricular year of an undergraduate Bachelor of Medicine, Bachelor of Surgery program. Deidentified data, related to the students' proficiency of the four selected skill sets and the students' academic performance: Grade-Point-Average, were retrieved. The data was analysed using SPSS for Windows version 27.0.

Results: Out of the 63 admitted students, 28 participated in the offered intervention. The correlational analysis showed how increase in the overall score of skill sets proficiency was significantly associated with Year $1 \mathrm{GPA}$ and cGPA. The students' proficiency in the respective skill sets, however, was independent from their Year 2 GPA. Additionally, the performance of the students seemed to be not associated with their proficiency scores in each of the selected skill sets, independently. 
50 Conclusions: The innovative intervention of developing selected skill sets constituted an 51 efficacious bridge to facilitate the secondary-to-tertiary education transition. Adapting such a 52 multi-dimensional, resilience building intervention holds the potential of facilitating the 53 students' entry into medical school and improving their performance. As the medical student 54 progresses, the acquired skills need to be continuously reinforced and effectively built upon.

Keywords: bridge to university; transition program; undergraduate medical education; academic performance; learning skill sets; self-regulated learning 


\section{Background}

Secondary-to-tertiary education transition is a significant milestone in the students' academic journey. The metamorphosis entails a physical and mental multi-dimensional adaptation to higher education frameworks and their expectations, self-regulated behaviors, and sociocultural and environmental influences. ${ }^{1}$ The teacher-driven structured, planned, monitored and evaluated school program renders the school-leaver unprepared for the independent autonomous sophomore, and for inhabiting an open-campus potentially experimental lifestyle. ${ }^{2}$ This highlights the importance of Self-Regulated Learning (SRL), and of crafting nurturing environments that inspire and empower students to create their own learning pathways. SRL relates to five elements of the individual students: cognitive and metacognitive, behavioral, and motivational and emotional. ${ }^{3}$ Self-regulated students are recognized as active learners, managing their own learning via monitoring and the use of metacognitive strategies. ${ }^{4}$ Accordingly, students' cognitive processing operates while planning, performing, and evaluating.

Health professions' education brings unique transformational challenges, in preparation for future career paths, most of which are associated with significant amount of lifestyle modifications and stressors. Multiple transitions, at admission (secondary-to-tertiary education), pre-clinical-to-clinical, and clinical-to-practice, form milestones demanding adaptation by the students and nurturing by the educators and by other environmental support mechanisms. ${ }^{5}$ The start of the educational journey in medical school requires building of resilience through early mastery of time management, modification of study methods to cope with quantum of cognitive burden, and evolution towards higher levels of analytical thinking. ${ }^{6-}$ ${ }^{9}$ It entails the recognition of the need for self-reliance and peer collaboration, reorientation to resources, and development of the capacity to handle success and reverses. The challenges of 
dealing with disease and facing death, to which the medical novice may have had little prior exposure, form the landscape against which a new professional identity will emerge. ${ }^{10,11}$ Tests of knowledge, skills, and competencies in a medical curriculum require both proficiency and test savviness which are key to success and contribute to perceived self-worth. ${ }^{12}$

The students' perception of their capabilities of coping with their workload affects their ability to achieve their academic goals. In a study on 244 students in first and second pre-med years and first to fourth medical years, the authors found that socially perceived perfectionism affected academic self-efficacy, which mediated academic burnout. The authors underscore the importance of educational and counselling interventions in mitigating the adverse outcomes on students through enhancing academic self-efficacy. ${ }^{13}$

A study on academic stress perception was conducted at the Lübeck Medical School using a Perceived Medical School Stress scale (PMSS-D) a validated tool which includes several stressors including workload, competition, social isolation, and financial worries. ${ }^{14,15}$ The survey was conducted at two identified milestones in an undergraduate medical program. Freshman students were surveyed at the end of the first year of study and sophomore students at the end of two years, upon taking the nation-wide progression exam at the transition between pre-clinical and clinical years. Higher stress scores correlated with lower academic performance. Also, older female students had higher stress scores.

A framework for comprehensive and coherent development of learning proposes a preinduction online course followed by a carefully designed induction phase with increasing personal tutor support and constant self-reflection by the student. ${ }^{16}$ The author emphasises the requirement of supporting academics with time, expertise, and incentives to enable commitment to this crucial early step of building capacity of learners. ${ }^{16}$ In a scoping review of learning support intervention programmes, during the first year of medical school, it was found that interventions could be identified as proactive or reactive addressing deficits or promoting 
development. ${ }^{17}$ The interventions addressed knowledge, and personal and professional learning skills, and program learning elements, and were delivered through a variety of institutional stakeholders and student-centred initiatives.

The difficulties students confront are variably coped with depending upon the level entry (i.e., undergraduate or graduate) and are influenced by individual-level characteristics. In all cases, adverse impacts can range from sub-optimal academic performance to adverse health outcomes, requiring attempts at prevention, early detection, and mitigation. ${ }^{18}$ Although this crucial phase of the educational transformation is both documented and has earned scientific exploration, programs that bridge and support the school-college leap are a recent phenomenon. ${ }^{17}$ Outcomes of such interventions have also not been extensively published, discussed, or translated into policy. ${ }^{2}$ A 'learning to learn' framework supported moving away from the deficiency model of focusing on remedying missing skills during the school to higher education transition. ${ }^{2}$ Instead, a 'holistic subject-specific approach' that supports the engagement and commitment of academic teachers to ensure the growth of independent learners was proposed. ${ }^{16}$

This study was therefore undertaken to implement and analyse the impact of an online multidimensional resilience building foundational program, designed to foster students' SRL. This intervention ran synchronously during the first curricular year of an undergraduate Bachelor of Medicine, Bachelor of Surgery (MBBS) program. Through this study, we investigated the efficacy of this intervention. We also analysed the association between the students' proficiency of the four selected sets of skills and their academic performance over time. Accordingly, our research question was: is the proficiency in the selected skill sets associated with the students' academic performance? 
Methods

\section{Context of the Study}

This study was conducted in the College of Medicine at the Mohammed Bin Rashid University of Medicine and Health Sciences (MBRU) in Dubai, United Arab Emirates. Students are admitted into the MBRU 6-year MBBS program directly from high school with no medicine foundation year. This MBBS program is divided into three phases, each of which has several components (phase 1- one year; phase 2- two years; phase 3- three years). Student progression to the next phase is subject to successful completion of the progression requirements along with the achievement of a minimum cumulative Grade Point Average (cGPA) at the end of the preceding phase.

\section{Description of the Intervention}

In the Academic Year 2018-2019, 63 (11 males and 52 females) students were admitted to the MBBS program at MBRU. The cohort intake is homogenous with respect to age and academic credentials, given the standardized admission selection processes and procedures. To ease the transition of the admitted high school students to the medical school, and to enable personal, academic, and professional development, the students were offered an online Multidimensional Resilience Building Intervention (MRBI) (Pearson College and Career Readiness Solution-All right reserved 2018).

The adapted intervention was developed by the system provider in alignment with the Personal and Social Capabilities (PSC) framework, and with the target of increasing the users' awareness, happiness, empathy, and resilience that are necessary for successful secondary-totertiary education transition. The PSC Framework, which pinpoints crucial soft-skill sets, was created to inform the development of educational products aimed at bridging the gap between 
secondary and tertiary educational phases, and at refining learning outcomes. The tool's developer identified six common categories of soft skills that can drive the learner's success in any learning setting: (1) Collaboration and Teamwork; (2) Communication; (3) Critical \& Creative Thinking; (4) Leadership; (5) Self-Management/Initiative \& Mindset; and (6) Social Responsibility (Figure 1). The proposed digital tool consists of 19 online modules listed in Table 1.

The implementation of the intervention was spearheaded by Advising Group composed of a selection of students' academic advisors (all of whom are faculty members) from the MBBS program in addition to professional administrative and technical members from the MBRU. The intervention was implemented in alignment with the SRL theories. Accordingly, the adaption occurred in three phases that are common across the main theories of SRL: preparatory, performance, and appraisal. ${ }^{19,20}$ As such, the participants' first exposure was during the new students' orientation at the beginning of the academic year, where representatives of the Advising Group facilitated for the students to initiate the preparatory phase. Thereafter, the students were enabled to deploy the four components integral to SRL: task definition, goal setting and planning, enacting study tactics and strategies, and metacognitively adapting studying. ${ }^{4}$ Throughout the performance phase, the assigned representatives of the academic members of the Advising Group played the role of a mentors, were they assumed that the students are self-directed, intrinsically motivated, have previous knowledge and experience, will form mental models through this learning and development experience, and use analogical reasoning as their knowledge base evolves. ${ }^{21}$ Thus, throughout the assigned 6 weeks, three reflection sessions ( 1 every 2 weeks) were conducted. This was done to foster SRL in the context of collaborative learning. ${ }^{22}$

Four out of the nineteen modules of the adapted online program were prioritized and purposefully selected as part of this transition. The selection was based on the perceived 
deficiencies identified at the same learning stage in previous intakes of the MBBS program. Accordingly, the selected modules addressed the following skill sets: Time Management (TM), Memory and Study (MS), Listening and Taking Notes (LTN), and College Transition (CT). The tool is supplemented with pre- and post-assessment and module has learning objectives where the achievement of the created objectives is gaged by post-assessment. The outcome of the assessment is reflected on a "Mastery Report" generated for individual student. Each student was given unique number and access code to the online tool in the orientation day at the start of the respective academic year. The use of the tool was not mandated. The students were offered an information session conducted during the orientation day to introduce the tool and to address the students' queries. Prior to starting the first module, the students were encouraged to complete the pre-assessment to have an insight into the initial mastery level of the four selected modules.

\section{Research Design}

A retrospective longitudinal study design was utilized. Ethical approval for the study was granted by the MBRU Institutional Review Board (Reference \# MBRU-IRB-2021-58).

\section{Data Collection}

Data related to the students' proficiency of the four selected sets of skills were extracted from the reporting dashboard (from the corresponding "Mastery Report"). This is linked with grade book, embedded in the software of the online tool, and corresponds to the learning outcomes of the courses. As for the data related to the students' academic performance, the cumulative/ semester Grade-Point-Average (GPA) for the students were retrieved from the Student Information Self-service (SIS). The extracted information from the students' records was 
retained in such a manner that subjects cannot be identified. Data were coded and linked through identifiers to the subjects.

\section{Data Analysis}

The quantitative data was analysed using SPSS for Windows version 27.0. The descriptive analysis constituted of computing an overall score of skill sets' proficiency (of all 4 selected skill sets 2 . Then, the mean and standard deviation were calculated for each skill set component, independently, and the overall score of skill sets' proficiency. The validity tests of Cronbach's Alpha and the Principal Component Analysis (PCA) were performed to ensure the internal consistency and check the external variance, respectively, of the overall score of skill sets proficiency, and that of each skill set component, independently (since each component is comprised of a set of skills) (Table 1).

To select the appropriate comparative analyses tests, a test of normality (KolmogorovSmirnov) was conducted for the annual GPA of Years 1 and 2, and of cGPA. The data of the annual GPA of Year 1 and that of the cGPA turned out to be normally distributed ( $\mathrm{p}=0.110$ and $\mathrm{p}=0.148$, respectively). As for the data of the annual GPA of Year 2, it turned out to be not normally distributed $(\mathrm{p}=0.005)$. Given the fair sample size, the Bivariate Pearson Correlations was used to assess the extent to which the academic performance of the students (GPA1, GPA2, and cGPA) can be explained by the corresponding students' level of proficiency of each skill set component and by all four sets together (i.e., the overall score of skill sets' proficiency).

\section{Results}

Out of the 63 admitted students, 28 (27 females and 1 male) participated in the abovementioned intervention (i.e., 44.44\%). The reliability score of Cronbach's Alpha for overall 
score of skill sets' proficiency was $67 \%$. When each skill set component TM, MS, LT, and CT was analysed independently the Cronbach's Alpha scores were 93\%, 88\%, 69\%, and $81 \%$, respectively. The percentage of the total average of the overall score of skill sets' proficiency turned out to be $32.15 \%$, as per Table 2. According to the PCA (Kaiser-Meyer-Olkin Measure of Sampling Adequacy), most of the variance can be explained by the instruments of each skill set component and the overall score of skill sets proficiency, which means these instruments is not only reliable but also, according to Bartlett's Test of Sphericity, valid to measure what it is intended to measure $(\mathrm{p}<0.001)$.

The mean and standard deviations of the performance of the students for years 1 and 2 on a GPA range of 1-4 were $2.83( \pm 0.74)$ and $2.83( \pm 0.99)$, respectively. The mean and standard deviation of the cGPA at the end of the study period was $2.92( \pm 0.70)$. The Bivariate Pearson Correlations showed how increase in the overall score of skill sets proficiency is significantly associated with academic performance of the students in year $1(\mathrm{r}=0.44, \mathrm{p}=0.019)$ but does not remain associated with their performance towards the end of year $2(r=0.327, p=0.089)$. Yet, the cGPA appeared to be significantly associated with the overall score $(\mathrm{r}=0.438, \mathrm{p}=0.020)$. Also, the performance of the students seemed to be not associated with their proficiency scores in each of the components, independently.

\section{Discussion}

This study showed that the intervention of developing the selected skill sets constituted an efficacious bridge in terms of facilitating secondary-to-tertiary education transition. The proficiency of the students in the respective skill sets, all together, was significantly associated with enhanced performance in the first year (i.e., Year 1 GPA) and cumulatively towards completion of the second year of the MBBS program (i.e., cGPA). Along those lines, it has been repeatedly suggested that entry to an undergraduate medical program entails a transition 
that calls for adaptation to the medical curriculum and a process of professional identity building. ${ }^{10,11}$ A positive learning environment is a key influencer of the overall educational experience in medical school in general, and in the early years of transition from school, in specific. A study on 4664 medical students of two cohorts from twenty-eight medical schools at 38 campuses demonstrated 15.6\% variation in Medical School Learning Environment Survey (MSLES) scores. ${ }^{23}$ As such, the researchers recommended closer examination of a host factors including but not limited to grading policies, administrative support, and existence of learning communities to enhance environmental positive influences in learning outcomes.

Students vary in their adaptation to this crucial leap depending on several internal and external factors. These factors include but are not limited to alignment of school syllabi with higher education academic path, suitability of learning styles, perceived self-efficacy, overemphasis on performance, mismatch between expectations and reality of selected career path, and weaknesses in self-regulation. Financial stress could make matters worse. Such stressors may precipitate or aggravate pre-existing, or de novo physical or psychological conditions. The number of stressors and the level of stress both play a significant role in academic performance. ${ }^{18}$ These determinants are particularly relevant to entry to undergraduate medical education as those who choose this professional path are usually aspirational high achievers. ${ }^{24}$ Hence, effective transitioning requires that the students consciously invest time and efforts, and are provided with the necessary support by their environments to circumvent their own internal vulnerabilities and the inevitable external challenges that they face at this crucial junction. Acquiring important skill sets like time management, organisation, and prioritisation as well as focused strategic study approaches become of paramount importance. ${ }^{12}$ In fact, the current study established that developing the combination of all four selected skill sets is what adds value (together and not in isolation) towards adapting to this transition, as reflected in the participants' academic performance. Therefore, the online intervention under investigation 
offered a holistic multipronged solution to a compounded transition challenge, where it was evident that the integrated whole, in terms of the educational offerings, was more than the sum of its individual components.

The intervention, investigated in the current study, appeared efficacious in the first year (i.e., Year 1 GPA) but not in the second year (i.e., Year 2 GPA). In other words, the proficiency in the selected skill sets successfully predicted academic performance in first year. However, as the students progressed to second year, the effect of the intervention dissipated. This finding encourages providing students with a refreshing course. It would also be helpful to offer the students complementary learning and development opportunities of more advanced and/ or focused skill sets appropriate to the next stage of learning. Relevantly, study time and study habits are known to have a variable relationship to performance. ${ }^{6}$ In a previously conducted study, student performance in medical school appeared to be better correlated with learning approaches, relative to learning styles. ${ }^{9}$ Thus, focusing on adaptive techniques that encourage strategic and deep learning approaches is likely to be most effective in supporting students as they progress in their educational trajectory. It is worth highlighting that the benefit accrued was independent of school-level or graduate-level entry to medical school.

The current study showed that having the intervention was better than not having it. Although the intervention was not efficacious in the second year (i.e., Year 2 GPA), adapting this intervention was still considered beneficial for the students given that the cGPA was significantly associated with the overall skill sets' proficiency. Similarly, a study on 120 health professions students from Kingdom of Saudi Arabia found that information discrimination, motivation, and metacognition were significantly associated with GPA, while a significant correlation was also found between time management and age. ${ }^{25}$ Also, in another insightful study on various aspects of time management among undergraduate engineering students and its impact on their grades, it was noted that despite the desire to be organised, students often 
failed to implement effective strategies to achieve time management. ${ }^{7}$ Consequently, they concluded that students' ability to set goals and prioritize activities measured as Perceived Control Of Time (PCOT) were the most significant factors that correlated with achievement of high GPAs. It is pertinent to note, mature students and female students are reported to demonstrate better time management skills but its correlation with academic performance is modest. $^{26}$

The findings of the current study also encourage adapting the utilized tools to support in predicting the students' readiness to transition to tertiary education. Overall, grades at school leaving exams and structured exam formats are the best predictors of performance at medical school. ${ }^{27}$ However, questions remain on validity of tools used and the weightage accorded to selection components. It is worth examining why despite selection to medical school based on similar cognitive and non-cognitive attributes, some students underperform. Those who fall back $a b$ initio in this transition require timely self-reflection to seek help, and closer formal and informal support by multiple agencies within the college to pre-empt, detect, and mitigate adverse outcomes. The tools used in this study, overall and for each skill set, independently: TM, MS, LTN, CT, all turned-out to be internally consistent/ reliable and externally valid. In other words, the components of the tools defined by the online intervention under investigation (Table 1) are worth leveraging as a means of evaluating the proficiency of high school graduates in the selected skill sets and their readiness to transition to universities, in general, and medical schools, in specific. Educational instrument employed to assess study skills, Learning And Study Strategies Inventory (LASSI) 10-subscale scores were used to compare 180 low and high academically performing medical students relative to internal and external examinations. Anxiety, Motivation, and Test Strategies were the sub-scales identified as significantly different between high- and low-performing students. ${ }^{12}$ The use of LASSI to identify specific areas of adaptation during the transition can be useful to provide targeted 
intervention in support of students found deficient. ${ }^{28}$ Potential learning gaps can help identify academic remediation to smoothen the transition.

It is established that the extent of self-directedness and SRL among learners is a good predictor of their academic performance around key junctions in their educational trajectory. ${ }^{8,29-31}$ The results of suboptimal academic performance in college after an outstanding school record has diverse impacts ranging from psychosocial retreat, loss of motivation, withdrawal from the program to, in more extreme cases, predilection to self-harm. It behoves educationists and student support agencies to devise appropriate strategies, such as that introduced in this study, to prevent the onset or at least decrease the likelihood of occurrence of those challenges. A study was conducted on 102 freshman medical students at the end of the first year of medical school to compare their SRL, academic achievement, and hours of self-study/ week to the last year of secondary school. Self-directedness at both phases and strategies for learning and assessment in college were considered protective against burnout. ${ }^{32}$ This finding reinforces the importance of basing initiatives aimed at secondary-to-tertiary education transition on SRL theories. This requires fostering the students' motivation and commitment to learn. ${ }^{29,33}$ It would also add value to consider not only the persons, but also their behaviours and environments, as indicated in the triadic analysis of SRL. ${ }^{19}$

The efficaciousness of the intervention under investigation encourages medical educators to think of innovative ways to proactively facilitate not only the entry into medical school transition but also ones that follow. Beyond the entry to medical school transition, pre-clinical to clinical transitions bring novel disruptors due to perceived or actual stress of inadequacies or incompetence which demand tackling through nurturing and empowerment. ${ }^{34}$ Transition programs to internship for example address "professional reflection, consolidation of knowledge, and social, emotional, and ethical growth" beyond the overt curriculum. ${ }^{35}$ Transition-To-Residency (TTR) pilot programs have been hailed as acceptable and feasible 
mechanism to make the final transition to graduate studies smoother. ${ }^{36}$ With this in mind, we propose an adapted framework of transition-support that aligns timing of the transition support and its context in a stepwise and sustainable fashion. It, thus, dynamically adapts to identified needs and provides the continuum to anticipated transition points leading to graduate medical education and the workplace. In the context of the MBBS program, the early transition support could employ tools that boost communication and a self-management/ initiative mindset. In the following pre-clinical years increasing levels of critical thinking and collaboration are required as enablers for professional growth. Integrated with clinical years and post-graduate training, social responsibility and leadership would determine development of the persona of the mature health professional along with academic accomplishment and competency in skills. Accordingly, based on the evidence gathered from this study, we propose a stage-appropriate adaptation support system contextualised to a stepwise transition-mitigation approach to supporting student resilience and progression in a medical education degree program.

This study has several limitations. First, the intervention (in alignment with the ethical principle of autonomy) was not mandatory but made optional. Thus, it was entirely up to the students whether, or not, they wanted to sign-up for the offered opportunity. This might have introduced a bias, where for example, those who chose to take part of the experience, were the ones who were more competent and perhaps better at self-directed learning. Second, the participants constituted a sample of a single cohort. Hence, the generalizability of this study's findings is limited to a population of students that are characteristically like that under investigation. It will be worthwhile to conduct follow-up studies that compare several programs across multiple institutions, preferably in different countries. Third, the deductive nature of the study, where it started with the intention of investigating the association of skill sets' proficiency with academic performance, limited the scope of analysis. Accordingly, future studies can 
inductively explore other antecedents to academic performance (e.g., demographic variables) that could play a moderating or mediating role in the association established in this study. Finally, our study did not focus on non-scholastic aspects of the student experience which could help evaluate non-curricular stressors that either contribute to or aggravate student nonprogression. Such variables could be of relevance given the complementarity of the social, cultural, symbolic, and economic capitals to the student's capital in determining both the intent to join medical school but inevitably the achievement of goal posts while navigating medical graduation. ${ }^{37,38} \mathrm{~A}$ study of such parameters would help in designing a 360-degree plan of action that begins before entry into the medical program, moulds to the progression level needs, and in later years, provides seamless support to transit to graduate medical education and the health professions workspace.

\section{Conclusions}

This study highlights the importance of developing a contextualized, evidence-driven intervention to proactively nurture selected skill sets among medical students to facilitate their education transitions, and in turn their academic performance and progression. Such an intervention should not be perceived as a one-time learning bridge around secondary-to-tertiary education, but rather a series of initiatives that address the specific needs of the medical students depending on the stage of their educational trajectory. This cascade of events will build upon each other, continuously reinforcing the acquired knowledge and skills. We recommend for all such activities to focus on fostering, first and foremost, the medical students' capacity for SRL.

\section{Abbreviations}


421 cGPA: Cumulative Grade Point Average MBBS: Bachelor of Medicine Bachelor of Surgery

422 CT: College Transition

423 GPA: Grade-Point-Average

424 IRB: Institutional Review Board

425 LASSI: Learning and Study Strategies Inventory

426 LTN: Listening and Taking Notes

427 MBRU: Mohammed Bin Rashid University of Medicine and Health Sciences

428 MRBI: Multi-dimensional Resilience Building Intervention

429 MS: Memory and Study

$430 \quad$ PCA: Principal Component Analysis

431 PMSS-D: Perceived Medical School Stress scale

432 PSC: Personal and Social Capabilities

433 SIS: Student Information Self-service

SRL: Self-Regulated Learning

TM: Time Management

436

TTR: Transition-To-Residency

437

438

\section{Declarations}

439 Ethics approval and consent to participate

440 Ethical approval for the study was granted by the MBRU Institutional Review Board 441 (Reference \# MBRU-IRB-2021-58). A retrospective longitudinal study design was utilized. 442 The Mohammed Bin Rashid University of Medicine and Health Sciences Institutional Review 
443 Board (MBRU-IRB) reviewed and approved the present study. Further clarification can be

454

455

459

460

461

462

463

464

465

466 5 obtained from the MBRU-IRB at irb@mbru.ac.ae. No questionnaire or survey was created or designed for this study. No students were enrolled for this study as the presented data were existing and retrieved from the record of an intervention introduced and made available for all new students admitted to MBBS program in the academic year 2017-2018 to enhance the teaching and learning at MBRU. All methods were performed in accordance with the relevant guidelines and regulations (Declaration of Helsinki), hence informed consent was waived off by the MBRU-IRP.

\section{Consent for publication}

Not Applicable.

554

\section{Availability of data and materials}

The datasets generated and/ or analysed during the current study are not publicly available as they form a part of the students' record at the university but are available from the corresponding author on reasonable request.

9

\section{Competing interests}

The authors declare that they have no competing interests.

\section{Funding}

No funding was obtained for this study.

Authors' contributions 
467 L.A. assisted with study design and interpretation of the data, had full access to the study data, 468 assumes responsibility for the integrity of the data and the accuracy of the analysis, and drafted 469 the manuscript.

470 F. O. \& R. L. assisted with interpretation of the data and drafted the manuscript.

471 A.KH. conducted the statistical analyses.

472 R. A. assisted with data collection.

473 All authors reviewed the manuscript and contributed to the final editing of the manuscript.

475 Acknowledgments

476 The Authors wish to thank the MBRU members who contributed to the implementation of the 477 Multi-dimensional Resilience Building Intervention including Jalal Mohamadeya (Smart 478 Services Department), Manar Abdullah (Student Services and Registration Department), and Ala'a Azayem (Digital Marketing- Communications and External Relations Department). 480 Also, they wish to acknowledge Dalia Leil from Pearson for the continuous support with the 481 technical aspects during the intervention implementation. 


\section{Tables}

Table.1 The intervention's modules and correspondent learning objectives of the implemented modules.

\begin{tabular}{|c|l|}
\hline & Intervention's Module \\
\hline 1 & College Transition \\
\hline 2 & Time Management \\
\hline 3 & Listening and Taking Notes in Class \\
\hline 4 & Memory and Studying \\
\hline 5 & Stress Management \\
\hline 6 & Reading to Learn \\
\hline 7 & Learning Preferences \\
\hline 8 & Test Taking Skills \\
\hline & \\
\hline 9 & Goal Setting \\
\hline 10 & Wellness \\
\hline 11 & Critical Thinking \\
\hline 12 & Communication \\
\hline 13 & Problem Solving \\
\hline & \\
\hline 14 & Workplace Etiquette \\
\hline 15 & Online Learning \\
\hline 16 & Create an Academic Plan \\
\hline 17 & Majors' Careers and Resumes \\
\hline 18 & Understanding Diversity and Ethics \\
\hline 19 & Understanding Growth Mindset \\
\hline & \\
\hline
\end{tabular}

\begin{tabular}{|c|c|c|}
\hline & Implemented Module & Learning Objectives \\
\hline 1 & College Transition & 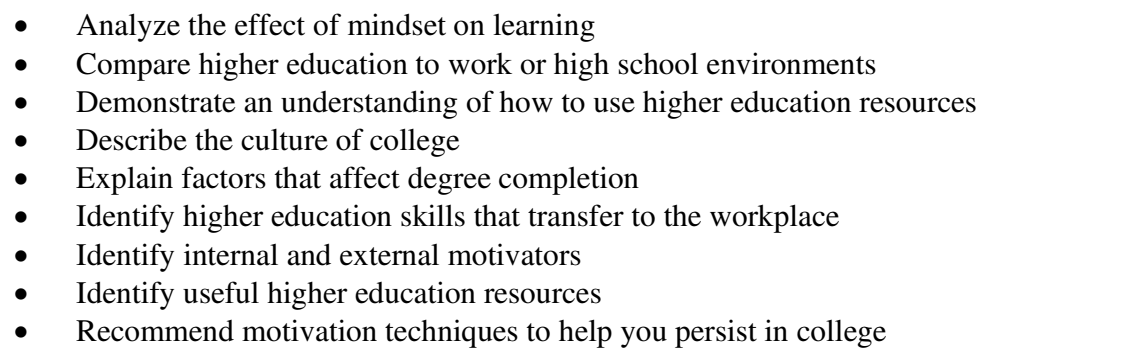 \\
\hline 2 & Time Management & 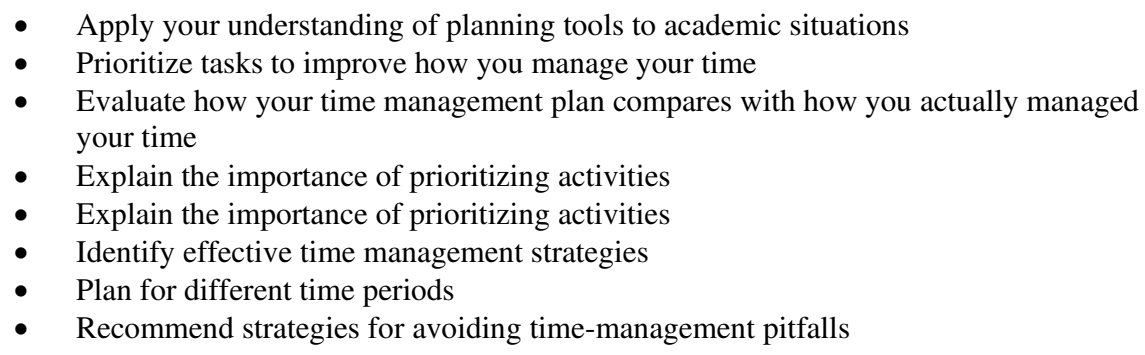 \\
\hline 3 & $\begin{array}{c}\text { Listening \& Taking } \\
\text { Notes }\end{array}$ & $\begin{array}{l}\text { - } \\
\text { - }\end{array}$ \\
\hline 4 & Memory and Study & 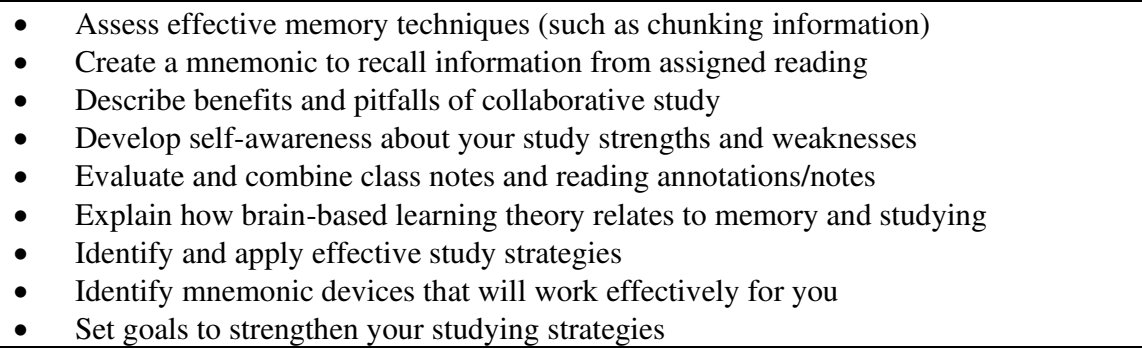 \\
\hline
\end{tabular}


Table.2 The percentage of the mean and standard deviation for each skill set component and for the overall score of skill sets' proficiency.

\begin{tabular}{|c|c|c|c|}
\hline Score & Number of Items & Mean (SD) & Percentage of the Mean \\
\hline TM & 8 & $2.46(2.82)$ & $30.75 \%$ \\
\hline MS & 9 & $3.36(2.87)$ & $37.33 \%$ \\
\hline LT & 8 & $2.39(1.93)$ & $29.88 \%$ \\
\hline CT & 9 & $2.71(2.42)$ & $30.11 \%$ \\
\hline Overall & $\mathbf{3 4}$ & $\mathbf{1 0 . 9 3 ( 7 . 2 0 )}$ & $\mathbf{3 2 . 1 5 \%}$ \\
\hline
\end{tabular}




\section{Figures}

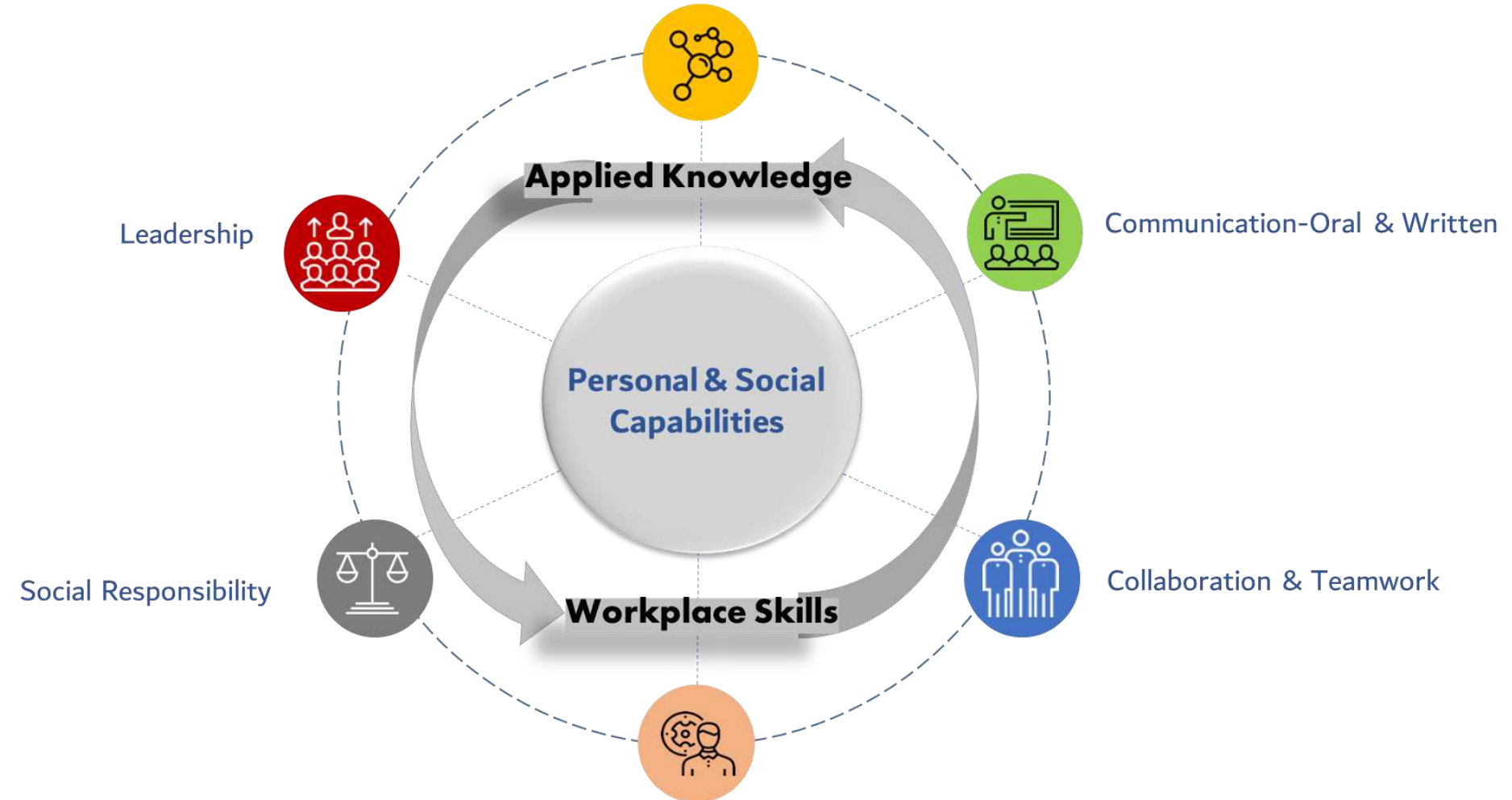

Self-Management/Initiative \& Mindset

Figure 1. Personal and Social Capabilities Framework

The framework identifies six common categories of soft skills that can drive the learner's success including: (1) Collaboration and Teamwork (e.g. perspective taking, coordination, empathy, trust, flexibility); (2) Communication- oral and written (e.g. persuasiveness, presentation skills, active listening, influence); (3) Critical \& Creative Thinking (e.g. problem formulation, problem solving, reasoning, extrapolation); (4) Leadership (e.g. managing self, integrity, working with others/teams, managing and planning, vision); (5) SelfManagement/Initiative \& Mindset (e.g. metacognition, ownership, goal orientation, growth vs. fixed mindset); and (6) Social Responsibility (e.g. ethics/integrity, community service, cultural awareness, sustainability). 


\section{References}

1. Matos Fialho PM, Dragano N, Reuter M, et al. Mapping the evidence regarding school-to-work/university transition and health inequalities among young adults: a scoping review protocol. BMJ Open. 2020;10(12). doi:10.1136/bmjopen-2020039831

2. Briggs ARJ, Clark J, Hall I. Building bridges: understanding student transition to university. Quality in Higher Education. 2012;18(1). doi:10.1080/13538322.2011.614468

3. Panadero E. A Review of Self-regulated Learning: Six Models and Four Directions for Research. Frontiers in Psychology. 2017;8. doi:10.3389/fpsyg.2017.00422

4. Winne PH, Hadwin AF. Studying as self-regulated learning. In: Metacognition in Educational Theory and Practice. The educational psychology series. Lawrence Erlbaum Associates Publishers; 1998:277-304.

5. Moro C, Spooner A, McLean M. How prepared are students for the various transitions in their medical studies? An Australian university pilot study. MedEdPublish. 2019;8(1). doi:10.15694/mep.2019.000025.1

6. Nonis SA, Hudson GI. Performance of College Students: Impact of Study Time and Study Habits. Journal of Education for Business. 2010;85(4). doi:10.1080/08832320903449550

7. Adams R v., Blair E. Impact of Time Management Behaviors on Undergraduate Engineering Students' Performance. SAGE Open. 2019;9(1). doi:10.1177/2158244018824506

8. Barbosa J, Silva Á, Ferreira MA, Severo M. Transition from Secondary School to Medical School: The Role of Self-Study and Self-Regulated Learning Skills in Freshman Burnout. Acta Médica Portuguesa. 2016;29(12). doi:10.20344/amp.8350

9. Feeley A-M, Biggerstaff DL. Exam Success at Undergraduate and Graduate-Entry Medical Schools: Is Learning Style or Learning Approach More Important? A Critical Review Exploring Links Between Academic Success, Learning Styles, and Learning Approaches Among School-Leaver Entry ("Traditional”) and Graduate-Entry ("Nontraditional”) Medical Students. Teaching and Learning in Medicine. 2015;27(3). doi:10.1080/10401334.2015.1046734

10. Chen DR, Priest KC, Batten JN, Fragoso LE, Reinfeld BI, Laitman BM. Student Perspectives on the "Step 1 Climate" in Preclinical Medical Education. Academic Medicine. 2019;94(3). doi:10.1097/ACM.0000000000002565

11. Cruess RL, Cruess SR, Boudreau JD, Snell L, Steinert Y. A Schematic Representation of the Professional Identity Formation and Socialization of Medical Students and Residents. Academic Medicine. 2015;90(6). doi:10.1097/ACM.0000000000000700

12. Khalil MK, Williams SE, Hawkins HG. The Use of Learning and Study Strategies Inventory (LASSI) to Investigate Differences Between Low vs High Academically Performing Medical Students. Medical Science Educator. 2020;30(1). doi:10.1007/s40670-019-00897-w

13. $\mathrm{Yu} \mathrm{JH}, \mathrm{Chae} \mathrm{SJ}$, Chang $\mathrm{KH}$. The relationship among self-efficacy, perfectionism and academic burnout in medical school students. Korean Journal of Medical Education. 2016;28(1). doi:10.3946/kjme.2016.9

14. Vitaliano PP, Maiuro RD, Mitchell E, Russo J. Perceived stress in medical school: Resistors, persistors, adaptors and maladaptors. Social Science \& Medicine. 1989;28(12). doi:10.1016/0277-9536(89)90351-1

15. Kötter T, Wagner J, Brüheim L, Voltmer E. Perceived Medical School stress of undergraduate medical students predicts academic performance: an observational study. BMC Medical Education. 2017;17(1). doi:10.1186/s12909-017-1091-0

16. Wingate U. A Framework for Transition: Supporting ?Learning to Learn? in Higher Education. Higher Education Quarterly. 2007;61(3). doi:10.1111/j.1468-2273.2007.00361.x

17. Kebaetse MB, Kebaetse M, Mokone GG, et al. Learning support interventions for Year 1 medical students: a review of the literature. Medical Education. 2018;52(3). doi:10.1111/medu.13465

18. Sohail N. Stress and academic performance among medical students. Journal of the College of Physicians and Surgeons-Pakistan : JCPSP. 2013;23(1):67-71.

19. Zimmerman BJ. From Cognitive Modeling to Self-Regulation: A Social Cognitive Career Path. Educational Psychologist. 2013;48(3). doi:10.1080/00461520.2013.794676 
20. Boekaerts M. Motivated learning: bias in appraisals. International Journal of Educational Research. 1988;12(3). doi:10.1016/0883-0355(88)90005-5

21. Zigmont JJ, Kappus LJ, Sudikoff SN. Theoretical Foundations of Learning Through Simulation. Seminars in Perinatology. 2011;35(2). doi:10.1053/j.semperi.2011.01.002

22. Hadwin AF, Järvelä S, Miller M. Self-regulated, co-regulated, and socially shared regulation of learning. In: Handbook of SelfRegulation of Learning and Performance. Educational psychology handbook series. Routledge/Taylor \& Francis Group; 2011:65-84.

23. Skochelak SE, Stansfield RB, Dunham L, et al. Medical Student Perceptions of the Learning Environment at the End of the First Year. Academic Medicine. 2016;91(9). doi:10.1097/ACM.0000000000001137

24. Silverman LK, Baska L. Counseling the Gifted and Talented. In: Silverman LK, ed. ; 1993.

25. Baothman A, AlJefri H, Agha S, Khan MA. Study Habits of Health Science Students at King Saud bin Abdulaziz University for Health Sciences, Jeddah, Saudi Arabia. SAGE Open. 2018;8(2). doi:10.1177/2158244018778092

26. Trueman M, Hartley J. A comparison between the time-management skills and academic performance of mature and traditional-entry university students. Higher Education. 1996;32(2). doi:10.1007/BF00138396

27. Patterson F, Knight A, Dowell J, Nicholson S, Cousans F, Cleland J. How effective are selection methods in medical education? A systematic review. Medical Education. 2016;50(1). doi:10.1111/medu.12817

28. Cook G, Sachs A, Wortham C. Learning and Study Strategies Inventory in the context of STEP 1 performance. MedEdPublish. 2021;10(1). doi:10.15694/mep.2021.000083.1

29. Bowman M. The transition to self-regulated learning for first-year dental students: threshold concepts. European Journal of Dental Education. 2017;21(3). doi:10.1111/eje.12193

30. White CB. Smoothing Out Transitions: How Pedagogy Influences Medical Students' Achievement of Self-regulated Learning Goals. Advances in Health Sciences Education. 2007;12(3). doi:10.1007/s10459-006-9000-z

31. Pintrich PR. A Motivational Science Perspective on the Role of Student Motivation in Learning and Teaching Contexts. Journal of Educational Psychology. 2003;95(4). doi:10.1037/0022-0663.95.4.667

32. Barbosa J, Silva Á, Ferreira MA, Severo M. Transition from Secondary School to Medical School: The Role of Self-Study and Self-Regulated Learning Skills in Freshman Burnout. Acta Médica Portuguesa. 2016;29(12). doi:10.20344/amp.8350

33. Pintrich PR. A Conceptual Framework for Assessing Motivation and Self-Regulated Learning in College Students. Educational Psychology Review. 2004;16(4). doi:10.1007/s10648-004-0006-x

34. Malau-Aduli BS, Roche P, Adu M, Jones K, Alele F, Drovandi A. Perceptions and processes influencing the transition of medical students from pre-clinical to clinical training. BMC Medical Education. 2020;20(1). doi:10.1186/s12909-020-02186-2

35. Teo AR, Harleman E, O'Sullivan PS, Maa J. The Key Role of a Transition Course in Preparing Medical Students for Internship. Academic Medicine. 2011;86(7). doi:10.1097/ACM.0b013e31821d6ae2

36. Wolff $\mathrm{M}$, Ross $\mathrm{P}$, Jackson J, et al. Facilitated transitions: coaching to improve the medical school to residency continuum. Medical Education Online. 2021;26(1). doi:10.1080/10872981.2020.1856464

37. Wouters A. Getting to know our non-traditional and rejected medical school applicants. Perspectives on Medical Education. 2020;9(3). doi:10.1007/s40037-020-00579-z

38. Bourdieu P. The forms of capital. In: Szeman I, Kaposy T, eds. Cultural Theory: An Anthology. John Wiley \& Sons Ltd; 1986:8193. 